\title{
The dispossessed of Egypt, Part I: Anatomy of hepatic-APR to environmental filth and VMAT2's variant-induced psychosis in aseptic rat models
}

\author{
JH Wassili and Cyril Baradaeus* \\ The Samaritan Biochemists, 279 Khaled ben Walied, Seidi Gaber, Alexandria, Egypt \\ It is better to be a human being dissatisfied than a pig satisfied. Better to be Socrates dissatisfied than a fool satisfied. And if a fool or the pig is of different opinion, it is \\ because they only know their side of the question: John Stuart Mill
}

\begin{abstract}
Experimentations were carried out in aseptic rat model to extrapolate, according to the yardstick of rigorous basic science, the neurology of a specific portrayal of a $\boldsymbol{V M A T 2}$ on societally characterized peers in terms of tracing hepatic APR to life-threatening neural provocation. In other words, it is a basic trial to link psychologically-induced hepatic injury to organic repercussions; primarily heart maladies, diabetes, gastritis, kidney-liver failures, infertility, etc. Ultimately, to mimic the exposure of the dispossessed congregated in snubbed subdivides within a walking distance to downtown Cairo; e.g., Necropolis and Zabbalein ghettos, two rat models were tackled. The daily routine of aseptic rats was imperilled according to a combination of different schedules of availing chew and water together with a neurological injury emanating from exposure to recorded sound of cats in fierce fighting. USN and random feeding of rat model evoked a different APR format of neuro-inflammation whose levels of APR proteins attained maximal and minimal changes at the $3{ }^{\text {rd }} \mathrm{d}$, which did not regress to aseptic levels post $\geq 15 \mathrm{~d}$ of neurotic intoxication. That may suggest possible defensive biological-internalization of concomitant neurological and organic injuries but not necessarily healing. Similarly, DLSN showed a typical profile of APR with regression of APR proteins closer to aseptic levels. As expected, DLSN of diabetic rats displayed a steady decrease in serum's free glucose together with concomitant increase in the relative concentrations of Ag, $\mathrm{Hp}, \mathrm{Fb}$ and At while those of Alb and Pre-Al remained close to healthy levels. Rats' provided with drinking water embracing DE-contaminants developed a range of mute APR on $3^{\text {rd }}-6^{\text {th }} \mathrm{d}$ of intoxication while substantial liver cirrhosis was visualized on d15. DLSN of pathological rat models at points of maximal APR, e.g., (i) carrageenan-injured (1d), (ii) TAM-cirrhotic (100d)- and (iii) DE-intoxicated (15d) rats, highlighted an unorthodox APR. For example, substantial $-76 \%,-51$, and $-33 \%$ depletion of Alb, Ag, and Fb respectively while pre-albumin was not detectable on $15 \mathrm{~d}$ of neurotically provoked DE model suggests substantial hepatic necrosis. Nonetheless, observed massive proteolysis of these serum proteins is deemed essential to provide intrahepatic cellular pool with monomeric carbohydrates and amino acids necessary for maintaining the remaining viable hepatocytes, however fatigued. These observations in rats' model paralleled the diagnosis of a very low percentage of defensive APR reactants and cardiac maladies-induced early mortality (24-50y range) in the environmentally and mentally-intoxicated dispossessed Egyptians. Nonetheless, the modest increase in the concentrations of Hg and At on $3^{\text {rd }} \mathrm{d}$ and $7^{\text {th }} \mathrm{d}$ of neurotic provocation of DE model may be indicative of increased efficacy of intoxicated hepatocytes undergoing possible proliferation. It remains, psychosis of fear-induced hepatic APR is a hereditary protocol that is retained into the long-range memory of rats regardless of the milieu of breeding, e.g., aseptic laboratory conditions or filthy sewages' milieu. Extrapolation of current data suggests humans may share certain distant evolutionary protocol(s) of neural behavioral patterns with early species, viz., de novo storage in giant marine snail Aplysia californica to reactions to noxious stimulation.
\end{abstract}

Although too late, our conclusion is a modest one of the many warnings to the infiltration of de novo mental aberrations and drug-resistant second-generations of mutated organic diseases into the industrialized world. Issues presented here remain worthy of further experimentations and elaborations in the advanced world that is mercilessly caught in-between the grinding stones of the ancient and contemporary mills, $\boldsymbol{V M A T 2}$ and scientific adventures of hexose polyester and GMOs respectively. Part II of our studies is pertaining to the relevance of bacterial and/ or enzymatic precipitation of organic maladies, e.g., malignancies, cardiovascular diseases, male ineptness, gastritis and kidney failures. Statistically, it is not a coincidence these injuries are 2-3 times rampant among the dispossessed dwelling in the filthy quarters of the city. Results involving deranged lipid distribution, bacterial pods and extraction of microplastics found in tissue of harvested fish from the heavily polluted River Nile and the Alexandrian shoreline will be published in Part III.

\begin{abstract}
Abbreviations: VMAT2: Vesicular monoamine transporter 2; MAOA: Monoamine Oxidase A; APR: Acute-phase response; DLSN: Day Light Scheduled Neurosis; USN: Unscheduled Neurosis; 2D-IEP: 2-dimension immunoelectrophoresis; HCV4b: Hepatitis C 4b; HBP: Helicobacter pylori; CHD: Cardiac heart diseases; RO: Reverse osmosis; TAM: Thioacetamide; DE: Diesel exhaust; HPE: Hexose polyester; GMO: Genetically modified organism; Necropolis: City of the dead; Zabbalein: Rubbish Collectors; Alb: Albumin; pre-Alb: Pre-albumin, Hp: Haptoglobin; At: $\alpha$-1-antitrypsin; Fb: Fibrinogen; Ag: $\alpha-1-$ acidglycoprotein
\end{abstract}

\section{Introduction}

It is our contention; one theorem and/ or a particular physicalorganic mechanism is dominating both, the bio-medical and psychological events leading to CHD, infertility, diabetes, kidney failure, etc. In general, elevated concentrations of APR reactants in human serum are portrayed as the fundamental causative factor leading to the precipitation of cardiac maladies. Thus, the current multidisciplinary presentation is an inquiry into the impact of hepatic APR to neurosis, in terms of the psychological aberrations of various divinities' yield of VMAT2 and the staggeringly polluted environment on the biological integrity of passive individuals. The recent incidents of well-organized

Correspondence to: Cyril Baradaeus, The Samaritan Biochemists, 279 Khaled ben Walied, Seidi Gaber, Alexandria, Egypt, E-mail: bioscience001@yahoo.com

Received: October 02, 2017; Accepted: October 21, 2017; Published: October 24,2017 
crimes in Cairo's slums, Upper Egypt and violating a female canine Anastasia, Figure 1, leaving the animal with traumatic body wounds including vaginal tissue damage are in glaring contradiction to the 7000-years most refined past of the Ancient Egyptian culture of the canine deity Anubis. Anubis was the deity elevated to weigh the heart of the diseased to decide his/ her fate, either into the darkness of the underworld or heavenly lodgings, Figure 2 . This exponential decline in the cultural stand of a nation with a distinct civilization supports our calling on the MDs and basic scientists to relinquish their safe laboratory corners to actively engage into a lengthy process to salvage the remnants of the traditionally abused dispossessed individuals from mental and filthy environments, CHD and other tropical maladies. This is to evade the anticipated exportation of a second generation filth-induced pandemic of mutated pathogens to large cities and neighbouring countries on the account of facile and affordable transportation.

At this particular moment, it is most relevant to interpret data pertaining to neurosis-induced hepatic APR in aseptic, cirrhotic and diabetic rat models according to VMAT2s' contradictory yields of various human tribes. Entertaining the hypothesis of particular proteins' synthesis in response to reaction(s) of a living cell to noxious stimuli yielding the synthetization of long range memory in giant marine snail Aplysia [1], we opted to probe the spectrum of APR of

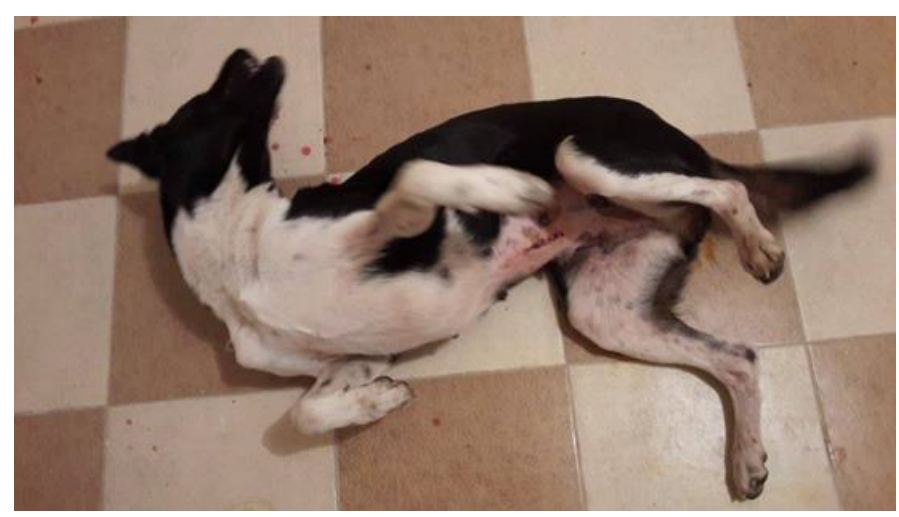

Figure 1. Abused female dog anastasia

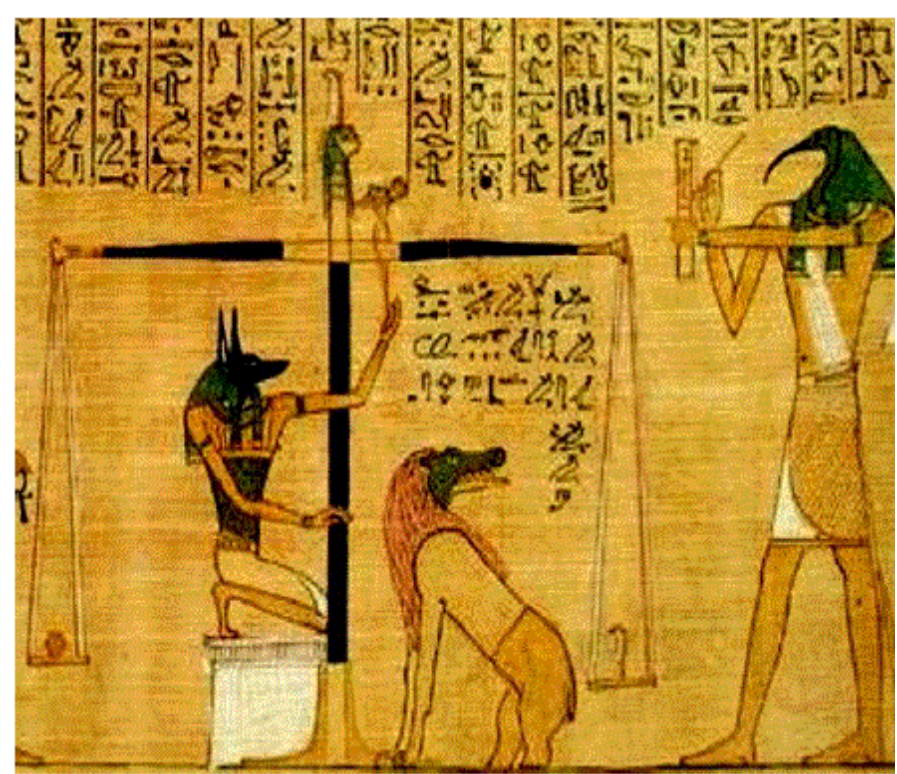

Figure 2. Ancient Egyptian Deity Anubis recessed genetic pool of fear to neurosis in a higher living entity, i.e., aseptic rat model. Unavoidably, it was mandatory to tackle the theorem of VMAT2 and implications therefrom, in terms of cardiac maladies associated to (i) fear and characterization and (ii) filthy cohabitation enclaves.

The philosophy of sciences has phenomenally advanced during the last seventy years, indeed. In lieu of the copious psychological search of Sigmund Freud, e.g., Moses and Monotheism [2], The Future of an Illusion [3], Civilization and its Discontent [3], The Rat Man [4], etc., most recently, Hamer hypothesized: faith that is most likely hardwired

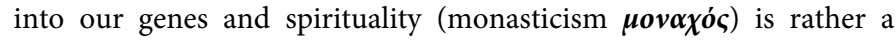
biological mechanism [5]. Furthermore, it was concluded: VMAT2 is the genetic vehicle that is expressing humans' predisposition to "mystic episodes" and spiritualism ultimately yielding the thesis of God. That is, the vesicular regulation of monoamine's transport and release, rather than the Freudian fear of life's inconsequential termination upon death, prompted the first conceptualization of a monotheistic deity of Akhenaten; the Sun Disk. Hamer's postulate is a stimulating hypothesis, indeed; therefore, in the language of basic chemists, tackling the by-products of VMAT2 should yield palpable biological responses. We found experimenting with the genetic pool of the long range memory of fear in rat model agrees with Kandel's postulate [1]. Nevertheless; quantitation of many aspects: (i) If environmental dictates and the cultural fabric of a tribe of devotees would permit dialogues among various theology proponents to hatch polytheistic, monotheistic entities or none at all, (ii) Is the yield and the inner fabric of VMAT2 heritable? (iii) The impact of daily psychological aberrations, e.g., paedophilia, necrophilia, incest and female mutilation on religiosity; remain to be tackled in terms of VMAT2's DNA-driven functions.

Present observations reason for neurotic maladies, hepatic and kidney dysfunction, diabetes and sterility which are plaguing a minority characterized by passivity and/ or aggression. Individuals of these two groups are enclaved in two notoriously filthy Zabbalein and the Necropolis ghettos respectively.

Considering the hypothesis of possible environmental and societal factors buffed VMAT2 to yield radically different theistic conclusion according to the cultural topographies of the location; it is amenable VMAT2's yield is reciprocal to the intellect of the tribe. Interestingly the very same theistic deity was sub-fragmented to many shades. In general, enlightened individuals, according to location, culture and abundance of resources provided fair distribution of nature's wealth among those who toiled to extract it would adopt a deity whose directives are in basic contradiction to the same theistic yield of barely cultured tribes? Nonetheless, subjects of both milieus expire according to different mechanisms of cardiovascular diseases. In brief, it is feasible to conclude different causative mechanisms of cardiovascular diseases among populations of advanced and less developed nations. Accordingly, protocols and procedures of medical managements will differ.

According to the current data and that of Kandel [1], it became relevant to anticipate the impact of a long term incubation of a stagnant and passive variant of VMAT2 in a medium supplemented with a corrosive set of theologies whose origins were prompted from an environment alien to cultural evolution and enlightened mental stimuli. The synthetic outcome of catabolizing principles of culturally distinct and enlightened divinities is bitterly fossilized sects. Rather than pursuing the attention of psychological and medical assistance, for self-preservation, narcissistically the fossilised sects would adopt defeated theologies and sublime their psychosis by downgrading the thoughts of the dominant bulk. 
It is most beneficial to bring the dilemma of the dispossessed who are tightly lodged in filthy ghettos, e.g., the Necropolis and Zabbalein within a hostile societal milieu of the city Cairo, to the attention of worldwide MDs, scientists and psychiatrists. Interestingly, in this particular case, both the dispossessed and peers are characteristically barren of culture and education. Our data disclosed minorities with radical dogmatic tendencies, masticated by characterization, are fertile to contracting stress related diseases, e.g., psychological anomalies related necrophilia, pedophilia and zoophilia, and organic gastritis and hepatic inflammations, CHD, diabetes and infertility. To top it, their inflammatory episodes are barren to known medications. Relatively, 2D-IEP of isolated serum of Zabbalein's occupants showed noticeably lessened immune-precipitates of identified plasma proteins relative to healthy Canadian which may suggest APR of fatigued hepatocytes to multi-inflammatory stimuli triggered by the environmental filth of said ghetto together with the prevalent stress of societal labelling. Thus, to inquire into the psychological domains of the destitute, it is imperative to define the psychological load of societal values and its ensuing biological disorders in terms of tracing APR to neurotic inflammation in animals' model.

\section{Experimental protocols and data}

Specific experimental protocols of psychotic perturbation of rat models are detailed within corresponding Tables' legend.

Glucose in animals' serum was assayed using in-house prepared reagents [6]; 2D-IEP was carried out as described earlier [6]. Antirat and human serum proteins were prepared in $2 \mathrm{Kg}$ rabbits. In all experiments, Specific pathogen-free rats $(100 \pm 10 \mathrm{gm})$ were kept $12 \mathrm{~h}$ light/12h darkness. USN model; twice per $\mathrm{d}$, rats irregularly availed chew and water for $10 \mathrm{~min}$, were neurotically unsettled at random intervals, 6-9 times/ $\mathrm{d}$ for 30 minutes each to a recorded sound of cats in fierce fighting either prior to, post or during availability of subsistence. DLSC model rats were freely offered chew and water while running at 9am, 1 and $6 \mathrm{pm}$ recorded sound of fighting cats for a period 20 minutes each.

\section{Discussion}

The essence of the current presentation is to differentiate as conceivable between the pathways of (i) environmental, (ii) neurosisinduced hepatic ARR, or (iii) a combination of both. Ultimately, (i) to hypothesize on APR as a likely yardstick to environmental-neurotic inflammation [7]; and (ii) stress of societal verbal harassments', characterization and rejection of a dispossessed Zabbalein's minority of a VMAT2's passive product, Figure 3, may promote organic injuries [8] including cardiovascular pathologies and pre-mature expiry.

\section{Impact of environmental filth and/ or societal milieu}

The following observation is indicative of the utter environmental filth encased the sporadic locations, Necropolis and Zabbalein, both are within a walking distance to middle class (if there is any at all) and rich downtown Cairo. Three adult females and a virgin tested positive for antibodies IgG and IgM to Treponema Pallidum, i.e., syphilis, in serum while not showing the organic symptoms associated with contracting the disease. Cultured vaginal swab of these cases revealed no active bacterial insults, which suggests possible contraction with variant subtypes of bacteria releasing proteins with some determinants similar to that of Treponema Pallidum. As well, $\geq 80 \%$ of elderly and young females tested positive for oxyuris in stool, a cause of infertility [9]? Moreover, $\sim 90 \%$ of the dispossessed tested positive for harbouring $H B P$ due to scavenging diet from mounds of scattered rubbish. Over and above psychological stress, according to currently established assumption, cultures of $H B P$ within the mucosal barrier of individual's

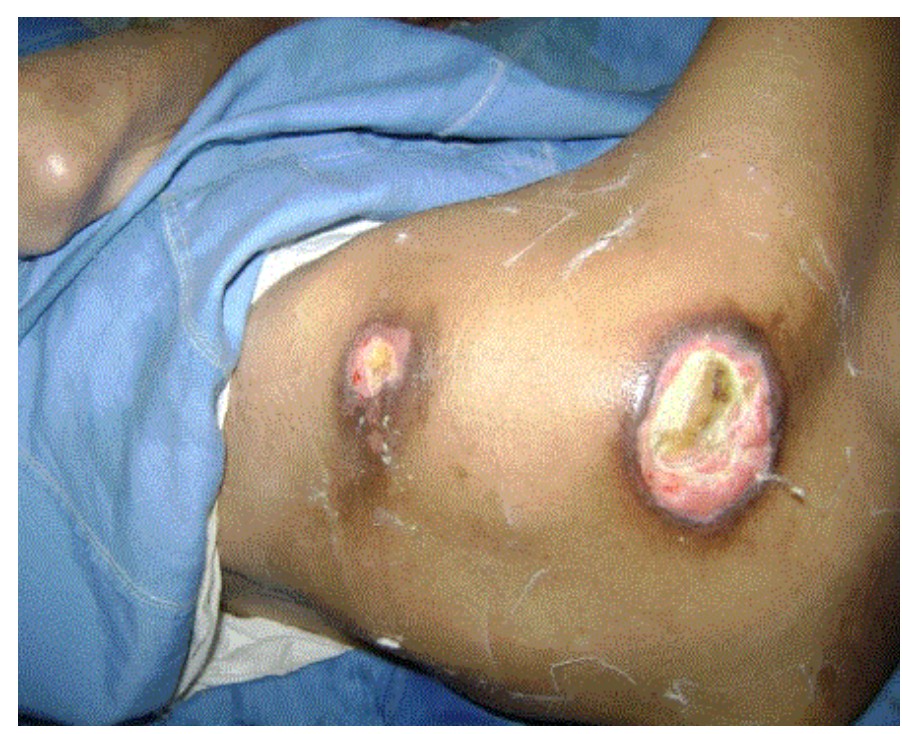

Figure 3. Skin-diseased individual (Zabbalein)

stomach lead to gastritis and ulceration. APR to gastritis is expected to induce CHD and early mortality. In general, regardless of sex, $\leq 10 \mathrm{y}$ children diagnosed with $H B P$ were at least $35-40 \%$ less in weight vis$\grave{a}$-vis the average Canadian children. Although, chronic infestation of $H B P$ into gastric mucosa precipitated depression of total serum protein relative to healthy Canadian controls, rocket and 2D-IEP of this group's serum were found to embrace $1.2-1.6 \pm 0.02$-fold $\mathrm{Fb}, \mathrm{Hg}$, and $\mathrm{Ag}$. Elevated levels of these APR proteins together with pre-existing high blood pressure may be one of the contributing factors [10,11] leading to early cardiac ailment among the young individuals' cohabitating these enclaves. Nonetheless, it is our contention HBP is not the sole factor provoking the biosynthesis and release of APR proteins, but psychological insults emanating from isolation and societal rejection of the dispossessed minorities together with environmental intoxication could be the prime factor contributing to the observed elevation of APR reactants. Accordingly, APR proteins may not the causative factor yielding cardiac maladies but rather a post-event hepatic reaction to cardiac ailments [12].

In the final analysis, $\dot{a}$ la the course of evolution at distant past, it was designed for large animals as dinosaurs to fall prey to much smaller ones to allow large scale evolution, currently the integrity of the bionetwork and its survival may necessitate the evolutionary inevitability of mammalian casualty to bacteria? The following may sound rather provocative: incubation of HBP into animals' gastric mucosa and subsequent precipitation of myocardial infarction and eventual death is a necessity within the mechanistic events of the cycle of life to curb the current overpopulation, however deserves some consideration.

Societal disfranchisements together with acute intoxication of the environment, e.g., air, potable water, basic food ingredients, etc., most likely precipitates low counts of male sperms with various deformities. This may account for the $\geq 3$ ratio of Female/Male of $\leq 10$ y group, i.e., an imbalanced reproduction of the two genders vis-à-vis the statistically accepted distribution in healthy societies, e.g., Canada [12]. In the absence of relevant sex education at early learning facilities, the immediate social impact of this radically crocked proportion of gender is increased inadequate sexual intimacy, necrophilia, pedophilia, zoophilia, abortions and female circumcisions, hymenorrhaphy, performed by barber doctors and filthy nurses. Thus, we are 
entertaining exponential elevation in mutated second-generation of social ills and venereal diseases, that is de novo subtypes of pathogens resistant to known medications. These de-novo pathogens of venereal diseases and societal aberrations could be exported to (i) close by dwellings of the economically privileged quarters of the city and (ii) overseas by means of facile and affordable air transportation and lack of convenient one-step test strips at points of entry. In this context, we observed the radical religiosity of the Necropolis's elders did not only capitulate the clan to collective neurosis-induced hepatic inflammation but also has enthused the homeless to establish an impenetrable belt of a psychological protective barrier. This is primarily, to maintain their dominion intact and resistant to manipulation by outsiders which is expected to exponentially multiply the possibility of breeding new subtypes of psychological and tropical viral and bacterial diseases within their realm.

\section{Neurosis-induced APR}

Aseptically raised laboratory rats divulged different hepaticinduced APR formats to the specificities of the neuro intoxication.

1. Day light USN evoked hepatic APR, Table 1A. That is, increased relative concentrations of $\mathrm{Ag}, \mathrm{Hp}$ and $\mathrm{Fb}$ with concomitant decrease of Alb and pre-Alb. However differed in details $v i s-\grave{a}$-vis the reported orthodox hepatic APR to inoculating rat hind paw with carrageenan. For example, contrary to $1 \mathrm{~d}$ maximal carrageenan-induced inflammation, day light USN-prompted hepatic injury to a maximal APR on the $3^{\text {rd }}$ $\mathrm{d}$ which recessed on the $7^{\text {th }}$, Table $1 \mathrm{~A}$. Moreover, said APR lasted for $15 \mathrm{~d}$ and did not regress to aseptic healthy values. Most likely, this phenomenon of mute regression of APR does not necessarily imply healing but rather loading the animal model with extra pathological injuries emanating from the neurotic uncertainty. Furthermore, added organic injuries precipitated by neurosis are not expected to display a typical APR trend as hepatic functional protocols are prioritizing in favour of defending the animal against the neurotic stimulant. The steady increase in the relative concentrations of serum glucose, $1.2 \pm$ 0.03 -fold on day 15 suggests either (i) substantial degradation of hepatic intracellular and skeletal glycoproteins to provide hepatic intracellular pool with free amino acids and glucose to biosynthesize defensive APR proteins and/ or (ii) neurosis-induced pancreatic dysfunction. It is safe to assume; the reported values of free circulating glucose may not reflect the active concentration of free circulating serum-glucose at these pre-determined points of time as a given proportion of serum's free glucose is already consumed in the biosynthesis of the APR reactants and maintenance of the hepatic intracellular organelles. This particular assumption of pancreatic dysfunction prompted a parallel trail of $D L S N$ on diabetic rats. In general, it is accepted; repeated episodes of psychologically-induced low-grade inflammation are assumed to activate the innate immune system to lay atherosclerosis and type-2 diabetes [7].

2. Nightly USN disclosed larger areas of Ag, At, $\mathrm{Hp}$ and $\mathrm{Fb}$ vis-àvis DLSN, e.g., Table $1 \mathrm{~B}$ versus $2 \mathrm{~A}$, which may highlight the specificity of said USN whose physical source, i.e., bodily tackling by cats is absent but stored in rats' long range memory (phobia?). On the other hand, APR to DLSN unveiled a classical regression of APR immuneprecipitates as of the $3^{\text {rd }}$ day of psychosis which suggests adaptation of animal's autoimmune defense to and internalization of scheduled repeated neuro-inflammation.

Although the above rational deemed it essential for rats to momentarily regain biological equilibrium post said two schemes of psychological injury; the inflammatory redness of rats' gastric mucosa
Table 1. \%Changes in area of immuno-precipitate APR proteins in aseptic rats induced by USN in (A) Day light and (B) Darkness of the night

\begin{tabular}{|c|c|c|c|c|c|c|c|c|c|c|}
\hline & \multicolumn{9}{|c|}{ A } & \multicolumn{5}{|c|}{ B } \\
\hline APR Protein & $0 \mathrm{~d}$ & $1 \mathrm{~d}$ & $3 \mathrm{~d}$ & $7 \mathrm{~d}$ & $15 \mathrm{~d}$ & $0 \mathrm{~d}$ & $1 \mathrm{~d}$ & $3 \mathrm{~d}$ & $7 \mathrm{~d}$ & $15 \mathrm{~d}$ \\
\hline Ag & 0 & 63 & 234 & 189 & 153 & 0 & 99 & 290 & 201 & 145 \\
\hline Hp & 0 & 21 & 36 & 18 & 12 & 0 & 27 & 45 & 27 & 15 \\
\hline Fb & 0 & 90 & 150 & 111 & 81 & 0 & 111 & 189 & 120 & 72 \\
\hline At & 0 & 51 & 72 & 62 & 42 & 0 & 63 & 108 & 102 & 33 \\
\hline Alb & 0 & -9 & -15 & -18 & -15 & 0 & -8 & -15 & -14 & -14 \\
\hline Pre-Alb & 0 & -8 & -12 & -15 & -9 & 0 & -8 & -9 & -11 & -15 \\
\hline Glucose & 1.00 & 1.04 & 1.07 & 1.16 & 1.20 & 1.00 & 1.06 & 1.12 & 1.16 & 1.22 \\
\hline
\end{tabular}

observed in all $15 \mathrm{~d}$ experimental animals is indicative of further bodily organic failure(s). Thus, animal's recognition of periodical stressful signals may activate a DNA stored and/ or innate biological defense to obstruct and internalize the anticipated, however perpetual neurotic stimuli in order to beget levels of APR proteins to the healthy aseptic levels. This is mainly to minimize bodily energy expenditure, i.e., to maintain lowest and/ or negative entropy of activation as possible. This APR could be interpreted as the biological outcome to an early warning mechanism that is optimized to contain the negative impact of long term psychological perturbation of the biological equilibrium leading to diabetic, gastritis, $\mathrm{CHD}$, etc. Thus, the brain may initiate or inhibit the inflammatory process, i.e., activates the hypothalamus-pituitaryadrenal axis to induce ARR where the parasympathetic nervous system mediates their detection by the central nervous system.

In conclusion, the following two mechanistic alternatives are suggested to rationalize the observed psychosis-induced APR, namely;

(i) the neurological or psychological coding of rat's reaction to external aggression that is threatening animals' security is a DNA-long acquired data. Thus, engraved into rats' DNA mapping, i.e., quantitatively inherited and is expected to be expressed at the opportune circumstance regardless of the conditions of animal's breeding. Accordingly, it could be hypothesized with some inevitability:

(a) Environmental aggression, particularly aridness may yield generations of occupants with mutated MAOA, thus Brunner syndrome, i.e., impulsive behavior as in arson, low IQ, hypersexuality as in paedophilia, necrophilia, zoophilia and violence, and

(b) Hepatic APR to perpetual aggression and disreputable sentiments of belligerence against a characterized sect of the populace could be DNA engraved, thus inheritable characteristics and

(ii) Subjecting aseptically raised animals to noise pollution of cats' aggression has decoded inflammatory sequence of events culminating into APR and organic injury.

Design of experimentations to characterize which of the two mechanistic routes above is the predominantly contributing path to the observed APR is feasible; however was not pursued further as it was not the main concern of the present hypotheses.

\section{DLSN of pathological rats revealed the following}

DLSN of diabetic rats: Imperilling diabetic rats to DLSN revealed excessive $15 \mathrm{~d}$ unyielding biosynthesis and release of hepatic Ag, Hp, At and $\mathrm{Fb}$, Table $2 \mathrm{~B}$. This observation may suggest elevated biosynthesis of serum and intracellular hepatic glycoproteins is an alternate post ribosomal pathway to level the excessively circulating glucose. Unless consumption of excess circulating glucose in diabetic model is bound to an event of inflammatory sensitization, this postulate fails to account for the substantially reduced relative concentrations of $\mathrm{Hp}$ 
Table 2. \% Changes in area immune-precipitate APR proteins in aseptic rats induced by DLSN in (A) Healthy and (B) Diabetic rats. DLSC model rats were freely offered chew and water while running at $9 \mathrm{am}, 1$ and $6 \mathrm{pm}$ recorded sound of fighting cats for a period 20 minutes each.

\begin{tabular}{|c|c|c|c|c|c|c|c|c|c|c|}
\hline & \multicolumn{9}{|c|}{ A } & \multicolumn{5}{|c|}{ B } \\
\hline APR Protein & $0 \mathrm{~d}$ & $1 \mathrm{~d}$ & $3 \mathrm{~d}$ & $7 \mathrm{~d}$ & $15 \mathrm{~d}$ & $0 \mathrm{~d}$ & $1 \mathrm{~d}$ & $3 \mathrm{~d}$ & $7 \mathrm{~d}$ & $15 \mathrm{~d}$ \\
\hline Ag & 0 & 72 & 183 & 129 & 63 & 0 & 76 & 201 & 250 & 255 \\
\hline Hp & 0 & 24 & 33 & 15 & 15 & 0 & 32 & 41 & 65 & 67 \\
\hline Fb & 0 & 92 & 120 & 91 & 63 & 0 & 115 & 132 & 156 & 149 \\
\hline At & 0 & 54 & 63 & 51 & 42 & 0 & 69 & 78 & 81 & 93 \\
\hline Alb & 0 & -10 & -10 & -15 & -12 & 0 & -3 & -1 & 1 & -3 \\
\hline Pre-Alb & 0 & -7 & -15 & -11 & -12 & 0 & 3 & -5 & -2 & 2 \\
\hline Glucose & 1.00 & 1.04 & 1.08 & 1.19 & 1.15 & 6.30 & 1.04 & 1.03 & 1.03 & 1.02 \\
\hline
\end{tabular}

and At in diabetic model post maximal release circulating glucose. Over and above detailed repercussions of radically intoxicated food ingredients, e.g., male ineptness, long term prejudiced characterization may rationalize the 3:1 ratio of the diabetic Zabbalein's occupants to contract CHD versus individuals dwelling healthier areas of the city, e.g., Heliopolis.

DLSN of DE intoxicated rats: According to data, Table 4A and visualization of fatty deposits in liver, maximal cirrhosis developed 10 - 20d post providing rats with DE-intoxicated water. Cirrhotic rats lost $7+3$ gm in weight. At $15 \mathrm{~d}$ point of time, 15 rats were $D L S N$ neurotically provoked. Three individuals expired on 6 and $13^{\text {th }}$ day of neurotic provocation.

Rats' provided with DE-intoxicated water developed a range of mute APR on $3^{\text {rd }}$ and $6^{\text {th }} d$ while visualization of liver cirrhosis was observed $\geq$ 7 times faster than TAM model. Contrary to the TAM model, d15 DEintoxicated rats' did not show signs of neither cirrhotic reversibility nor Pre-Alb were detectable as of providing rats with fresh water, Table 4A. DLSN of typically carrageenan-injured, TAM and DE-cirrhotic rats highlighted the onset of an unorthodox biosynthesis of APR reactants, Tables 3A, 3B and 4B. For example, substantial $-76 \%,-51$, and $-33 \%$ depletion of $\mathrm{Alb}, \mathrm{Ag}$, and $\mathrm{Fb}$ respectively, Table $4 \mathrm{~B}$, was noted while pre-albumin was not detectable in DLSN of DE model. This observation is most likely the optimization of the progressive hepatic necrosis together with the necessity of massive proteolysis of these particular serum proteins to provide intrahepatic cellular pool with monomeric carbohydrates and amino acids necessary for maintaining viability of fatigued hepatocytes. On the other hand, $15 \mathrm{~d}$ neurotic provocation of DE-intoxicated and TAM-cirrhotic rats retained a modest elevation of At and $\mathrm{Hp}$ while carrageenan injured model showed tangible increase in levels of Ag, $\mathrm{Hp}, \mathrm{Fb}$ and At, Table 3A, 3B and 4B. This unorthodox APR may suggests a mute hepatic proliferation is taking place within the injured remnant of hepatic mass and/ or increased efficiency of the intoxicated hepatocytes to biosynthesize these APR reactants. These observations in rats' model parallel the diagnosis of a very low percentage of defensive APR reactants and early mortality (24-50y range) in the Zabbalein's dispossessed Egyptians.

Absolutely above observation ridicules the robotic, alas feverish notions of banning smoking in restaurants, banks, hotels, governments' and public offices. The mind-defeating reality is: considering the economically biased distribution of the populace within different quarters of a typically crowded North American city, all are living in a non-stop 24h/day/week/year inhalation of DE-polluted air without any measure, if there is any at all, taken to remedy this irrevocable threat. It is obvious to a goat's head, correcting the situation would necessitate major overhaul of the protocols of energy expenditure which may directly contradicts the military-industrial industry. We dare claim scientific and medical research to manage the copiously toxininduced liver and cardiovascular diseases, cancer, etc., is an absurd avenue that is best labelled as a waste of time. Nonetheless, remains a necessary cosmetic façade to pharmaceutical-human greed. A more palatable and most realistic alternative is preventive measures. That is to courageously decide on curbing societal reliance on crude oil. This alternative remains a farfetched pipe-dream, however.

\section{In the final analysis}

1. Over and above long term contracts of a wide range of infectious tropical diseases by the dispossessed of the Zabbalein, Figure 3, and Necropolis ghettos, it is well established; the processing of the psychological overload of demeaning characterization [8] sand over crowdedness of occupants of said two ghettos by the amygdala would activate an alarm system. That is the hypothalamic pituitary adrenal axis and the sympathetic nervous system. Very likely, this neurotic activation would yield stress related hepatic inflammation ultimately prompting the release of APR reactants into circulation, concomitantly hastening diabetes, gastritis, and cardiovascular maladies. In this perspective $\geq 12 \%$ of the passive male population of the Zabbalein ghetto is experiencing substantially low counts of deformed or immobile sperms, predominantly diabetic and is in a long term contract with atherosclerosis, HCV4b and autoimmune diseases climaxing into early mortalities. By contrast the cohabitants of the Necropolis are inflexibly devout, radically belligerent and dominated with psychological aberrations. Together with prevailing illiteracy-induced low self-esteem, the Necropolis commune is plagued with the prevalent addiction to drugs particularly Sildenafil, equally by females and males, frequent sex crimes fueled by intolerance, incest, etc. Immediate and uncompromising cessation to females abuse, viz., Figure 4, that is

Table 3. \% Changes in area immune-precipitate APR proteins to DLSN in (A) Carrageenan inflamed and (B) TAM cirrhotic rats. 3A: DLSN was carried out on carrageenan inflamed rat model $1 \mathrm{~d}$ post inoculation of rat's hind paws with $0.1 \mathrm{ml}$ of $1 \mathrm{~g}$ carrageenan $100 \mathrm{ml}^{-1}$ saline. 3B: DLSN was carried out on $100 \mathrm{~d}$ post TAM (300 $\mathrm{mg} \mathrm{L}^{-1}$ drinking water) induced liver cirrhosis in rat.

\begin{tabular}{|c|c|c|c|c|c|c|c|c|c|c|}
\hline & \multicolumn{9}{|c|}{ A } & \multicolumn{5}{c|}{ B } \\
\hline APR Protein & $0 \mathrm{~d}$ & $1 \mathrm{~d}$ & $3 \mathrm{~d}$ & $7 \mathrm{~d}$ & $15 \mathrm{~d}$ & $0 \mathrm{~d}$ & $1 \mathrm{~d}$ & $3 \mathrm{~d}$ & $7 \mathrm{~d}$ & $15 \mathrm{~d}$ \\
\hline Ag & 122 & 90 & 123 & 57 & 49 & -40 & -38 & -51 & -35 & -60 \\
\hline Hp & 30 & 19 & 26 & 20 & 19 & 295 & 198 & 167 & 120 & 12 \\
\hline Fb & 102 & 80 & 95 & 98 & 100 & 15 & 5 & -4 & -14 & -35 \\
\hline At & 80 & 73 & 70 & 65 & 70 & 160 & 151 & 128 & 102 & 13 \\
\hline Alb & -9 & -15 & -25 & -30 & -38 & -20 & -28 & -35 & -47 & -64 \\
\hline Pre-Alb & -15 & ND & ND & ND & ND & -21 & -25 & -42 & ND & ND \\
\hline Glucose & 1.00 & 0.92 & 0.95 & 0.93 & 1.03 & 0.94 & 0.83 & 0.75 & 0.71 & 0.62 \\
\hline
\end{tabular}

Table 4. $\%$ changes in area of immuno-precipitates APR proteins to (A) DE-induced cirrhosis and (B) DLSN in DE cirrhotic rats. 4A: Daily, rats were provided with drinking water contaminated with DE-intoxicants. DE of a 5-7 y consumed engine, of a typically crowded Cario circulating transport vehicle filled with low quality diesel, was discharged through well-engineered piping with safety pressure valve into distilled water (5 L supplemented with $50 \mathrm{ml}$ each pure ethanol and cotton seed oil to trap lipophilic intoxicants) for $20 \mathrm{~min}$. $4 \mathrm{~b}$ : DLSN of DE-induced liver cirrhosis in rats. All entries, Table $1-4$, data are the averages of three determinations. Uncertainties are: $\mathrm{Ag}( \pm 21 \%), \mathrm{Hp}( \pm 9 \%)$, $\mathrm{Fb}( \pm 25 \%), \mathrm{Alb}( \pm 5 \%)$, pre-Alb( $\pm 6 \%), \mathrm{ND}$ denotes Not Detectable

\begin{tabular}{|c|c|c|c|c|c|c|c|c|c|c|}
\hline & \multicolumn{9}{|c|}{ A } & \multicolumn{5}{|c|}{ B } \\
\hline APR Protein & $0 \mathrm{~d}$ & $1 \mathrm{~d}$ & $3 \mathrm{~d}$ & $7 \mathrm{~d}$ & $15 \mathrm{~d}$ & $0 \mathrm{~d}$ & $1 \mathrm{~d}$ & $3 \mathrm{~d}$ & $7 \mathrm{~d}$ & $15 \mathrm{~d}$ \\
\hline $\mathbf{A g}$ & 0 & 90 & 103 & 45 & -31 & -32 & -18 & -23 & -39 & -51 \\
\hline Hp & 0 & 19 & 26 & 20 & 86 & 81 & 108 & 117 & 100 & 12 \\
\hline Fb & 0 & 80 & 95 & 98 & -10 & -12 & 3 & -9 & -18 & -33 \\
\hline At & 0 & 73 & 70 & 65 & 127 & 110 & 98 & 28 & 48 & 5 \\
\hline Alb & 0 & -17 & -30 & -39 & -56 & -42 & -51 & -59 & -67 & -76 \\
\hline Pre-Alb & 0 & ND & ND & ND & ND & ND & ND & ND & ND & ND \\
\hline Glucose & 1.00 & 0.92 & 0.95 & 0.93 & 1.03 & 0.94 & 0.83 & 0.75 & 0.71 & 0.62 \\
\hline
\end{tabular}




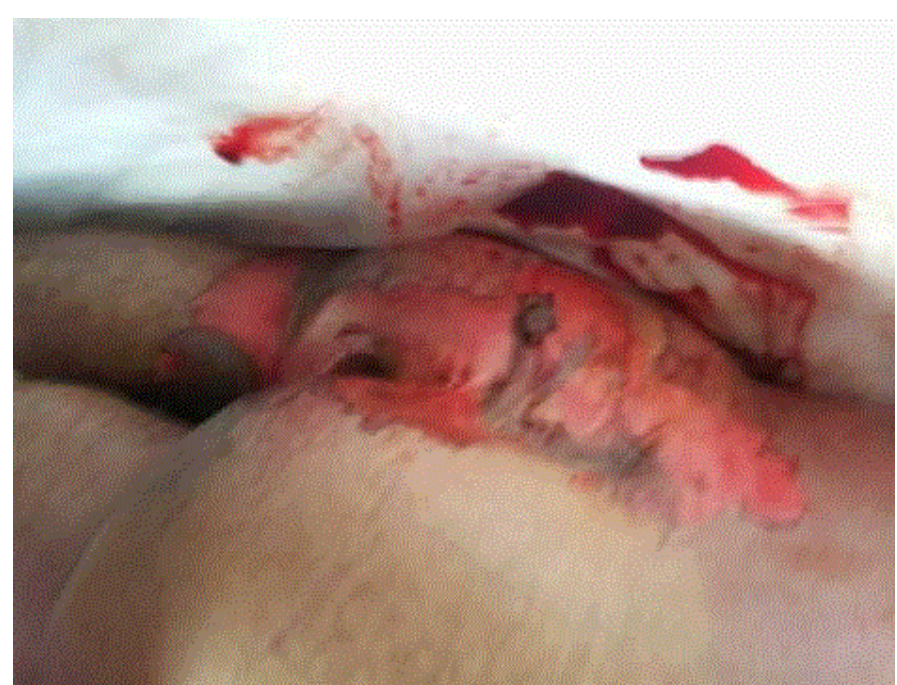

Figures 4. A female victim of brutality (Necropolis)

manifested on three levels; namely, (i) in the Necropolis ghetto, females are forced to active copulation as of tender age with sons, brothers or fathers and are obliged to abort the unexpected pregnancies by unskilled and utterly filthy midwives and at best barber doctors in insanitary milieus, (ii) elders promoting pedophilia, necrophilia, female-children marriages and bodily mutilation; i.e., females' circumcision performed by barber doctors. Well-planned psychotherapy of the dramatically increasing population of sexually-inept males to protocols of healthy management of the phobia of fear of female sexuality is deemed essential. In a characteristically male chauvinist society, female sexuality is a convenient façade to the chronicity of Egyptian males' impotence emanating from acutely intoxicated environment, addiction to narcotics and staggering low hygiene, viz., the recent absurd call of two devout Egyptian parliamentarians to check the virginity of females prior to admission into higher education?

2. With regard to the Zabbalein's lodgers, similar to DLSN of DE cirrhotic rats, once the mental essentials of the primordially stored memory of fear is tackled by a life-threatening neural signal, said biological protocols would evoke an unorthodox APR for a proportional period of time and would not recess to aseptic levels upon terminating the psychological-toxic stimulus. That is the genesis of long term contract with organic maladies, cardiovascular, diabetes, gastritis and kidney's dysfunction is partly different from that recognized in the advanced milieu.

3. Thus, VMAT2 yield of hostile and arid climatic setting is equally inhibiting corresponding dwellers of the joy of mental labour and modernizations to attain more graceful lives but rather acquiescent to mules and donkeys are common means of transportation. While other tribes, capitalists or communists, who coerced the product of VMAT2 into the side lines, managed to innovate more efficient means of transportation; vehicles, trains and jets. Finally, they had their foot print on the moon and reduced time span of communications into seconds, the internet, cell telephones, etc. Thus, it is most advantageous to print concerns without inhibition and the linguistic ridicule of the "politically acceptable statements". It is our contention; the psychological manipulation of 1909 and 1916 of Gertrude Bell and E.T. Lawrence respectively and the past eight-years of negatively disastrous political slope of experimenting with the Arab Spring is reminiscent to the uncertainties which preceded the 1914s and 39s. The glaring difference is the news of the 1915s' Ermeni Soykırım $ı$ and the 1939s' die Endlösung der Judenfrage were rather mute during the combat's years, in contrast remains of the victims of the Arab Spring were scattered in the streets of Cairo's Maspero 2011, North American, European, Russian and Chinese cities. Principally, regardless of the bitter and costly societal mayhem where it was triggered, intuitively according to the laws of science, the Arab Spring may initially display a rather short-lived term of success with handsome dividends to its tailors. Nonetheless, it is doomed to failure with worldwide calamities of pollution and long-term negative impact as importation of aggressive second generations mutated diseases. These mutated diseases are incurable by conventional drugs viz., Figures 5 and 6 . In this regard, the case of the North American mother of two who expired of massive sepsis in response to scratching her hand while nursing her backyard, Figure 7, ridicules the arrogant invincibility of superior circuitry at USairports. For safe transportation, travelers are asked to remove their shoes to step bare footed on synthetic mat. However, in less than few minutes, with the newly arriving passengers from arid countries and the uncontrolled flux of refugees, the mat will become an active breeding medium for bacterial and mutated second-generation skin diseases. It is equally distributing, all possible pathogens are freely carried to various destinations and/ or dwellings by all-innocent passengers. This mechanism should be interrupted with deep sanitation of travelers' feet with concentrated chorine disinfectants prior to searching and loading aircrafts with controlled sanitary discarding of mats. Concomitantly, in collaboration with Freudian psychiatrists, it is deemed essential to untie the product of rhythmic process of tutoring as of milk suckling age to VMAT2's products which facilitates the adaptation of a specific short term stimulations of a long term memory stored way of life with possible aberrations of individuals' DNA.

4. We are hypothesizing; although VMAT2-goaded humans to theorize abundant poly- and monotheistic deities, the rate-limiting step was the contradicting cultural and environmental contributions. Collectively, these factors sculpted various deities' $\boldsymbol{\theta} \boldsymbol{\varepsilon} \boldsymbol{o} \boldsymbol{\tau} \boldsymbol{\tau} \boldsymbol{\tau} \boldsymbol{\tau} \boldsymbol{\alpha} \boldsymbol{i s}$ with a plague of uncertainties. The major unsettling conclusion of this presentation is: aridity of the habituating milieu hatched and etched current dwellers' long range memory and DNA respectively with earlier cultural backwardness and precipitates of acidic societal discords. Flagrant unequal distribution of natural products among workers toiled to extract it from nature is the main ingredient in the cultures of discontent and upheaval. Accordingly, a particular VMAT2's yield was fashioned to authenticate their consumerism, i.e., genuine loss of innovation and the joy of hard toil. In contrast the

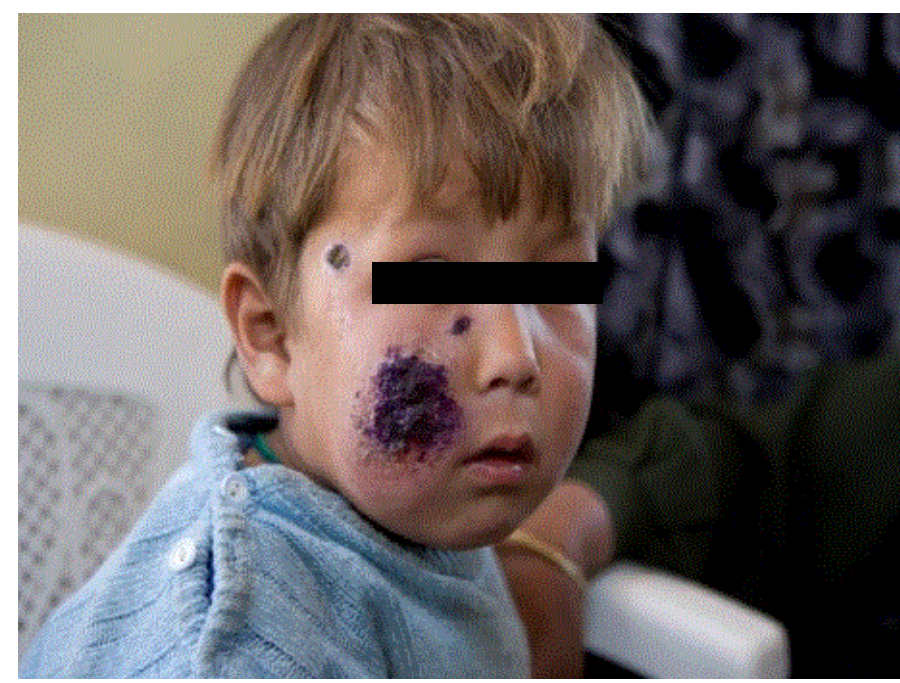

Figures 5. Afghani with cutaneous leishmaniasis 


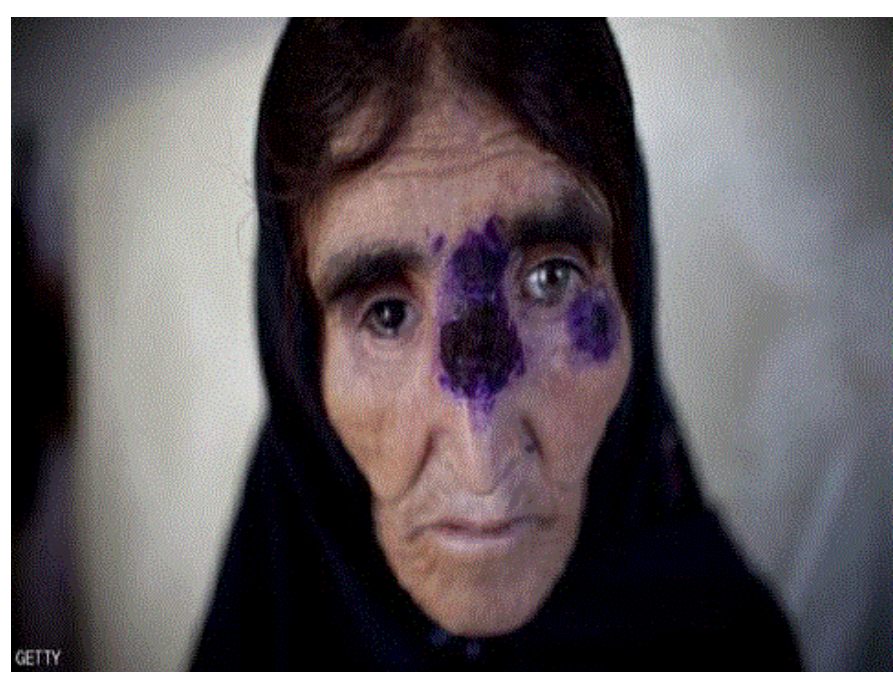

Figures 6. Syrian refugee with cutaneous leishmaniasis

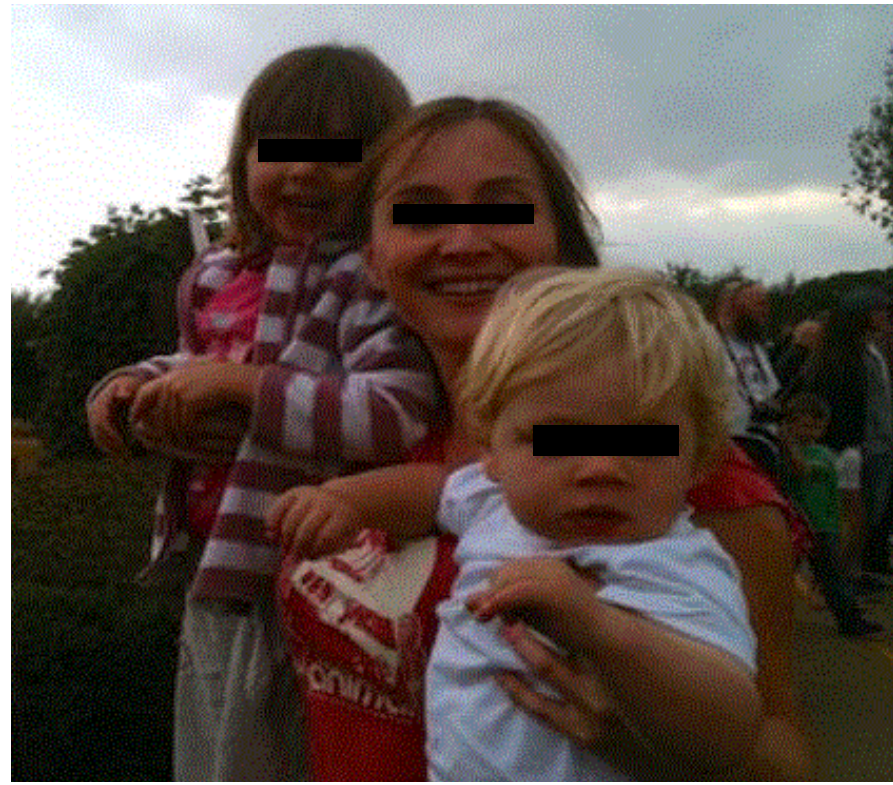

Figure 7. A mother expired of sepsis in response to scratching her hand while nursing her backyard

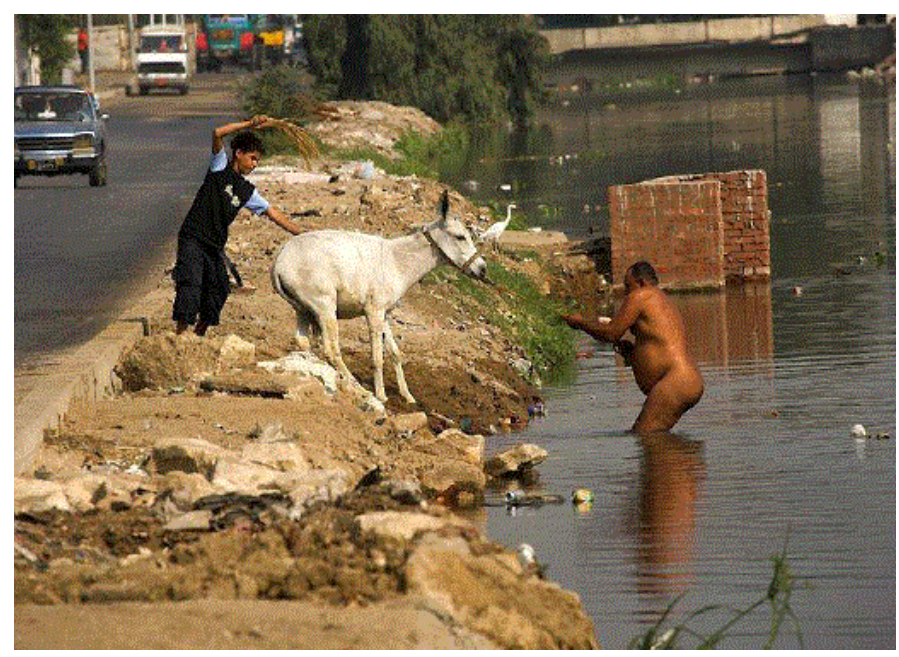

Figure 8. Typical abuse of the River Nile by contemporary Egyptians sophisticated cultural context of the Egyptians at the time withstood, for a short period of time, the evolution of the well-established Amon anthropomorphism to Amenhotep IV's monotheism (Aten) which was exported to the world at large. The inevitable question is: was Amenhotep IV conceptualization of Aten's monotheistic theme the baptism of the dictatorship of Monotheism that is void of Polytheisms' freedom of choice and/ or an Ancient Egyptian curse which outsiders happily adopted to consume themselves, e.g., WWI, WWII, WTC, Afghanistan, Iraq, Libya, Yemen?

5. The VMAT2 is supposedly the same very inheritable code within humans' DNA matrix regardless of geographical location unless a particular location is plagued with environmental hostility to the basic milieu of survival which may conclude an architecturally wrecked VMAT2? It is also plausible to damage VMAT2's gene of a given tribe with unwavering psyche tailored $\dot{a}$ la natural abundance and distribution of wealth, according to deep-seated stimulating factors. Thus, leaning in favor and/ or denial of a given VMAT2 theological portrayal is most likely a personal choice that is proportional to upbringing, or simply the outcome of an individualistic VMAT2? As it is the case for centuries of disastrous political-theological grappling with the outcome of variant VMAT2's; scientific inquiry à la Kandel [1] may blunt the very many rough edges of VMAT2's conclusions?

6. The outcome of transgenic humans, chimeras or hybrids, used to (i) model specific human diseases and (ii) biosynthesize recombinant pharmaceutical proteins and xeno-organs for human therapy or industry (spider goat) is rather clouded with uncertainty. Food basic sources are polluted as well, e.g., transgenic salmon was genetically engineered to reduce the cycle of its adult size into half, as well organic diets are gradually replaced with mutant harvests, GMOs and synthetic chemicals; HPE, etc. The interesting probe here is: how the product(s) of VMAT2 would judge deceased humans with increasingly replaced tissues with higher proportions of animal, bacterial or viral components? Hypothetically, increased proportions of animal tissues in future humans would likely evoke a de-novo critical modification of VMAT2's outcome which may impel a different visualization vis-à$v i s$ the ones known and rewriting of the psychological and behavioral inclinations of transgenic entities, e.g., tendencies to mate with animals, cannibalism, etc. A Darwinian-devolution of humans to a synthetic chimera?

7. Multidisciplinary preventive schemes embodying interwoven biomedical, psychological and education parallels are deemed essential to remedy the encasing of a characterized minority by a domineering variant of VMAT2. It is safe to assume malevolent interpretations of VMAT2's product are expected should it be mediated via $X X Y, X Y Y$ or hostile environment-driven MAOA and CDH13' human warrior genes' arbiter. In this context, comments of the Nobel Laureate DH Hamer on the males' lust to copulate with animals, Zoophilia, in terms

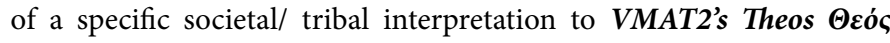
dictates are most pertinent to issues tackled in this chapter. The data available is; the Ancient Persians artistic articulation of zoophilia and homosexual tendencies elaborated in the artistic remnants of Ancient Greece and Rome were extrapolated to 2015 desert-dwellers taking turns masticating their depraved libido with a donkey. Although, the P.E. Trudeau's conceptualization of "just-society" and R. Levesque thesis on the distinctness of minorities are absolutely alien to the wrecked populations' of very many societies, in this particular instance; an international daring scheme to detoxify the shrinking two green stretches of the river Nile is an urgent task. That is, an absolute ban on use of herbicides and pesticides together with using, à la Israel, desalinated water, supplied by giant RO units built by seashores, as 
the main source for potable water and irrigation. On the long run, the RO alternative will avail the opportunity to wash the utterly intoxicated banks of the river Nile off the embodied residual toxins. Most importantly is educating the population to respect the source of their daily life, the river Nile, Figure 8 , which currently may sound an impossible dream, but why not? A scholar gracefully coined human determination as "There are those that look at things the way they are, and ask why? I dream of things that never were, and ask why not?" Similarly, another humanitarian on August $28^{\text {th }}, 1963$ had a dream of cleansing psychological domains of intoxicants. Most amazingly pitiful is the narcissistic pomposity of the current semi-illiterates (if educated at all?); irrespective of the solid scientific data incriminating pollution as the fundamental causative factor underlying the wide spread of de novo diseases as of malignancies, staggering male impotence, cardiac, kidney diseases, pollution of water resources and disturbance of the rhythmic cycle of nature: Pollution Factor is a Chinese Conspiracy to Impede their Industrial Progress and Quality of Life?

\section{Dedication}

To Naguib Sawiris, the philanthropist who indisputably registered his resources and social status in favor of the dispossessed.

\section{References}

1. Kandel ER (2002) The molecular biology of memory storage. A dialog between genes and synapses. Bioscience Report 21: 565-611.

2. Freud S (2010) Der Mann Moses und die monotheistische Religion, Knopf publications, 1939; Kindle edition in English 2010.

3. Freud S. Die Zukunft einer Illusion, Hogarth Press, London, 1928; and Das Unbehagen in der Kultur, 1930 Freud S (1930) Civilization and its Discontents, Internationaler Psychoanalytischer Verlag, Wien. [Crossref]
4. Freud S (1909) Rat Man Bemerkungen über einen Fall von Zwangsneurose.

5. Silveria LA (2008) Experimenting with spirituality: analysing The God Gene in a nonmajors laboratory course. CBE Life Sci Educ 7: 132-145; Hamer D (2005) The God Gene: How Faith is hardwired into our genes, Anchor Books ISBN 0-385-72031-9.

6. Seltzer HS (2009) Determination of Glucose in serum, J Am Med Assn. 1956; 162 , 1234-1237; Olsen RG, McCammon JR, Yohn DS, Simplified procedure for preparation of specific antibodies to gamma globulins; Applied Microbiology, 1970; 20, 75-77; Smith R. Two dimensional electrophoresis: An over view Methods. Mol Biol 519: 1-16.

7. Libert C (2005) Inflammation: A nervous connection. Nature 2003; 421, 328-329; Borovikova LV, Ivanova S, Zhang M, et al. Vagus nerve stimulation attenuates the systemic inflammatory response to endotoxin. Nature 2000; 405, 458-462; Black PH. The inflammatory response is an integral part of the stress response: Implications for atherosclerosis, insulin resistance, type-II diabetes and metabolic syndrome X. Brain Behav Immun 2003; 17: 350-364; Wellen KE and Hotamisligil GS. Inflammation, stress, and diabetes. J Clin Invest 115: 1111-1119.

8. Sexton ME (1990) Alienation, dogmatism, and related personality characteristics. J Clin Psychol. 1983; 39: 80-86; Pfeifer S, Waelty U. Psychopathology and religious commitment-a controlled study. Psychopathology 1995; 28: 70-77; Francis LJ. Neuroticism and intensity of religious attitudes among clergy in England J Soc Psychol 1992;132: 577-580; Biegel K, Lester D. Religiosity and psychological disturbance. Psychol Rep 67: 874

9. Neri A, Tadir Y, Grausbard G, Pardo J, Ovadia J, et al. (1986) Enterobius (Oxyuris) vermicularis of the pelvic peritoneum--a cause of infertility. Eur J Obstet Gynecol Reprod Biol 23: 239-241. [Crossref]

10. Singh RK, McMahon AD, Patel H (2002) Prospective analysis of the association of infection with Cag A bearing strains of helicobacter pylori and coronary heart disease. Heart 88: 43-46.

11. Jain S, Gautam V, Naseem S (2011) Acute-phase proteins: As diagnostic tool. J Pharm Bioallied Sci 3: 118-127.

12. Wassili JH, Baradaeus C (2012) Ghetto poverty and pollution in Egypt: A deadly threat for Western countries caused by new infectious mutants. A cultural, social and microbiological synopsis. Inflammation \& Allergy - Drug Targets 11: 406-419.

Copyright: (C2017 Wassili JH. This is an open-access article distributed under the terms of the Creative Commons Attribution License, which permits unrestricted use, distribution, and reproduction in any medium, provided the original author and source are credited. 